\title{
Incentivos Fiscais às Cooperativas
}

WALMOR FRANKE

Magistrado aposentado; ex-Membro do Conselho Nacional de Cooperativismo

Com o sistema tributário instituído pela Emenda Constitucional n. ${ }^{\circ} 18$, acolhido, com alterações, na Constituição de 1967 e mantido, na sua essência, na Lei Magna em vigor, tombaram as isenções anteriormente concedidas pelos Estados e Municípios às sociedades cooperativas.

2. Na vigência do antigo imposto de vendas e consignações, os Estados de São Paulo e Rio Grande do Sul, onde o cooperativismo apresenta os mais altos índices de desenvolvimento, isentavam, via de regra, dentro de certos limites, as cooperativas daquele tributo.

Substituído o IVC pelo ICM, passaram elas a ser tributadas por esse imposto, definido, constitucionalmente, como imposto sobre operações relativas à circulação de mercadorias realizadas por produtores, industriais e comerciantes (Const. art. 23, II).

3. As antigas isenções desapareceram, definitivamente, por força do Ato Complementar n. ${ }^{\circ} 34$, de $30-1-67$, que no seu artigo $2 .^{\circ}$ preceitua :

"A partir de $1 .^{\circ}$ de março de 1967 , são revogadas, para todos os efeitos legais, quaisquer disposições de lei, decretos e outros atos que tenham outorgado ou venham a outorgar isenções, reduções e outros favores fiscais, relativamente aos impostos sobre vendas e consignações e circulação de mercadorias, não previstos nos convênios e protocolos a que se refere 0 artigo anterior ou nos já celebrados em conformidade com o que nele se dispõe". 
Os "convênios" a que aludia o dispositivo, seriam aqueles celebrados, nos termos do Ato Complementar n..$^{\circ} 34$, artigo $1 .^{\circ}$, por "Estados ou Territórios situados em uma mesma região geoeconômica para estabelecer uma política comum em matéria de isenções, reduções ou outros favores fiscais, relativamente ao imposto sobre circulação de mercadorias".

Não nos consta que, no exercício dessa competência, Estados-membros das duas regiões geo-econômicas do País (Centro-Sul e Norte-Nordeste) tenham celebrado entre si convênios, instituindo isenção total ou parcial do ICM para saídas de mercadorias, cuja circulação seja promovida por sociedades cooperativas.

4. Entre outras ocorrências previstas no artigo $10^{\circ}$ do Decreto-lei n. ${ }^{\circ} 406$, de 31-12-68, opera como fato gerador do ICM a saída de mercadorias de estabelecimento comercial, industrial ou produtor".

Por outro lado, depois de estabelecer que "contribuinte do imposto é o comerciante industrial ou produtor que promove a saída da mercadoria...", o Decreto-lei n. ${ }^{\circ} 406$ preceitua no $\S 1 .^{\circ}$ do artigo $60^{\circ}$ :

"Consideram-se também contribuintes :

I. As sociedades civis de fins econômicos, inclusive cooperativas que pratiquem com habitualidade operações relativas à circulação de mercadorias".

5. Na sistemática da cobrança do ICM tem sido utilizado o instituto jurídico do "contribuinte substituto" atribuindo-se a responsabilidade pelo crédito tributário do ICM a terceira pessoa (comerciante, industrial, cooperativa etc.), vinculada ao fato gerador da respectiva obrigação" (Código Tributário Nacional, art. 128).

Assim, o agricultor que dá saída à sua produção, vendendo-a, por exemplo, a um comerciante ou industrial, não recolhe, pessoalmente, o ICM, cujo pagamento, ao revés, será obrigatoriamente feito pelos comerciantes ou industriais (contribuintes substitutos) que adquiriram o produto.

6. A fim de aliviar o impacto inicial da cobrança do tributo sobre o valor da produção primária posta, originariamente, em circulação pelos agricultores e pecuaristas, Estados houve que lançaram mão do artifício do "diferimento da incidência". 
Desse modo, não haverá pagamento do ICM nessas unidades federativas quando o agricultor ou pecuarista promover a saída de sua produção para estabelecimento comercial, industrial ou cooperativo, ficando a cargo desses estabelecimentos recolherem o imposto após nova saída que, por sua vez, venham a dar aos produtos recebidos.

7. O Decreto-lei n.o 406/68, admitindo, implicitamente, como fato gerador do ICM a entrega de produtos feita pelo cooperado à sua cooperativa, isentava do imposto :

"as saidas de mercadorias de estabelecimentos de produtos para estabelecimento de cooperativa de que faça parte, situado no mesmo Estado" (art. 1. ${ }^{\circ}, \S 4 .^{\circ}, \mathrm{IX}$ ).

Este dispositivo acha-se reproduzido no inciso IX do art. $1 .{ }^{\circ}$ da Lei Complementar n. ${ }^{\circ} 4$, de 2 de dezembro de 1969.

8. Nos Estados, em que não existe o "diferimento da incidência", a isenção ratificada pela Lei Complementar n. $0^{\circ} 4 \mathrm{em}$ favor do produtor cooperativado melhora inegavelmente a posição das cooperativas, face aos estabelecimentos comerciais ou industriais que, como adquirentes do produto, se acham onerados, desde logo, com o recolhimento do imposto.

Não ocorre o mesmo nos Estados que, como, por exemplo, o Rio Grande do Sul, instituíram o sistema do "diferimento da incidência".

Dentro deste sistema, sem embargo da isenção prevista na Lei Complementar n. 4 , em benefício do cooperado que transfere sua produção à cooperativa, tanto o comerciante ou industrial, que adquire originariamente produtos agropastoris, como a cooperativa, que os recebe dos seus associados, se encontram, perante o fisco, na mesma situação: o comerciante e o industrial recolherão o ICM, tal como a cooperativa, quando promoverem a saída do produto em direção ao mercado.

9. Ora, é evidente que, neste regime a "isenção" do ICM, outorgada pela Lei Complementar n. ${ }^{\circ} 4 / 69$, em nada modificou a posição das cooperativas de produtores rurais perante o fisco, desde que as legislações estaduais que adotam o "diferimento da incidência" as equiparam, inteiramente, no que respeita à forma e ao momento do recolhimento do imposto, às empresas lucrativistas, comerciais ou industriais, que adquirem, na sua origem, a produção agropastoril. 
10. Não se pode desconhecer que o ICM, quando recai sobre operações que tenham por objeto produtos agropecuários, repercute, em regra, regressivamente, isto é, onerando o vendedor. ${ }^{1} \mathrm{O}$ comerciante ou industrial, que adquire do pequeno agricultor o produto primário, leva em conta que, além do preço a ser pago, Ihe caberá recolher, em momento oportuno, o ICM incidente sobre o valor da compra. Procura, por isso, transferir esse ônus, regressivamente, ao vendedor do produto, pagando-lhe, dentro dos limites da conjuntura, o menor preço possível. Assim, por exemplo, ao invés de $\operatorname{Cr} \$ 1.000,00$ pagará ao agricultor, apenas ao redor de $\operatorname{Cr} \$ 840,00$, pois é sobre esse valor que satisfará o ICM pela alíquota de $16,5 \%$.

Nasce daí, naturalmente, o convite à evasão fiscal. Surge a figura do "atravessador", que compra o produto primário, subtraindo-se ao pagamento do tributo. E porque não paga o ICM (e muito bem sabe como fazê-lo) poderá oferecer ao produtor primário um preço maior do que o que vigora, correntemente, no mercado, para as operações tributadas.

11. O princípio hedonístico, posto em relevo pela ciência econômica, atua, por igual, no subjetivismo dos agrupamentos cooperativos. É compreensível, pois, que muitas vezes o agricultor cooperativado, sob o acicate de uma necessidade imediata, volte as costas à sua cooperativa, vendendo os seus produtos ao "atravessador", porque este the oferece a vantagem aparente de um sobre-preço, em relação ao preço-base que aquela credita ao cooperado. Assim procedendo, o cooperado, na realidade, se ilude a si mesmo, pois enfraquece a cooperativa, que é seu órgão de defesa, reduz-lhe o volume de negócios, dá origem a uma capacidade ociosa, sem contudo permitir que a cooperativa proceda, desde logo, a uma redução correspondente em suas despesas operacionais.

Nestas condições, o atual critério de tributação, pelo ICM, da produção agropastoril no âmbito da economia cooperativada, dá lugar a defecções de cooperados e desvios de produção, através de um sistema de evasões ilegais dificilmente controláveis, passando a cooperativa, tal como o próprio fisco, a sofrer materialmente as conseqüências da sonegação em curso.

12. Na França, que não tem as dimensões continentais do Brasil e onde a vida econômica se desenvolve sob a vigilância

1. Cf. Dr. JOSE MORSCHBACHER, Súmula de Direito Tributário, ed. 1968, pág. 136. 
de um aparelhamento fiscal sumamente eficiente, a sonegação foi calculada por MIDDENDORF em $40 \%{ }^{2}$. "As avaliações mínimas, afirma FRANÇOIS SELLIER, estimam que a fraude fiscal, na França, diminui de 300 a 400 bilhões as receitas públicas"2a .

Não há negar que, na opinião dos fiscalistas, é muito diffcil precisar a quanto atingem as evasões tributárias ${ }^{3}$. Certo é, porém, que elas existem em todas as latitudes e já agora estudadas como objeto de novas disciplinas científicas : a "sociologia fiscal" e a "psicologia social do imposto"4.

Como assinala GERLOFF : "A cobertura das despesas por meio da tributação, considerada esta como tomada coativa de recursos, retirados da economia privada, sem contraprestação, colide, geralmente, com a resistência das economias tributadas. A submissão à prestação tributária é sentida pelo obrigado como um agravo. FUISTING opina a propósito: "Quem considerar as relações à luz da realidade, não se entrega, nessa matéria, a nenhuma ilusão. O entendimento, haurido na concepção altamente moral do Estado, de que constitui uma honra participar dos seus encargos, jamais encontrará acolhida nos amplos círculos do povo"s.

do diz:

Não se discrepa dessa opinião FRANÇOIS MOMBERT, quan-

"Variando o acento, pode-se afirmar com ARDANT que todos os sistemas fiscais são "sistemas restritivos da liberdade", mas evidentemente com largas diferenças de grau e de sensibilidade por parte dos contribuintes".

"Pode-se, portanto, constatar, e isto não é novidade, que todos os contribuintes sempre procuram reduzir a carga de suas

2. Apud GUY houchoN, Psycho-Sociologie de la Fraude Fiscale in "En Hommage a Victor GOTHOT", 1962, pág. 377.

2a. Morale et Vie Économique, Paris, 1959, pág. 85.

3. Cf. Prof. JOHN F. DUE, Jornadas internacionais de Derecho Fiscal, Buenos Aires, 1961, pág. 10 .

4. Cf. FRANÇOIS MOMBERT, Problèmes de Sociologie et D'Économie Fiscale, in Revue de Sciences Financières, ano 1967, t.59, pág. 94 e segs. 441 e segs.; G. SCHMOLDERS, Psychologle Sociale de I'Impôt, in Revista cit., tomo 54, pág. 399; W. GERLOFF, Steuerwirtschaftslehre, in Handbuch Finanzwissenschaft, 2a., 1956, pág. 292.

5. Handbuch der Finanzwissenschaft, cit., pág. 294. 
contribuições, seja legal ou ilegalmente, ou porque desaprovam as ideologias e as restrições em que se baseia esta fiscalidade, ou porque ela não mais Ihes deixa (consoante seus próprios julgamentos) os meios de viver segundo suas idéias e pela forma reclamada pelo seu "status", ou mesmo porque ficam impedidos de acumular, desde que entendam que isso se torna necessário para a conservação de sua "posição" social ou econômica (pois a acumulação faz parte do "status" do burguês)" 6 .

Informa SCHMOLDERS que num inquérito efetuado em 1961 na Alemanha, a maior parte das pessoas inquiridas não colocava o "pecador fiscal" (vale dizer, qualquer pessoa que se torne culpável de fraude fiscal) no mesmo pé de um ladrão ou de um embusteiro, mas o qualificavam unicamente como "astucioso homem de negócios"; a fraude fiscal é, pois, considerada como ato quase estranho a uma apreciação "moral", como um fenômeno geral, quando não uma necessidade da vida econômica"7.

M. DUBERGE, em pesquisa realizada, na França, sobre a psicologia do imposto, verificou que não menos de $88 \%$ das pessoas interrogadas "aprovam a fraude fiscal, a desculpam ou, quando a condenam, o fazem exclusivamente porque se consideram penalizadas por não pertencerem a uma categoria que não pode fraudar ${ }^{8}$.

A fraude fiscal continua a ser, portanto, para a maior parte dos contribuintes, um problema de consciência - já posto em relevo por São Tomás de Aquino - e diante do qual o responsável se reserva o poder de julgar, em consonância com os seus próprios critérios, da legitimidade da norma tributária.

13. Nas zonas rurais, observa GERLOFF, há menos compreensão a respeito das necessidades da imposição fiscal do que nas cidades $^{9}$. Não é, pois, de estranhar que o camponês, quando o "atravessador", vezeiro na sonegação, lhe oferece qualquer vantagem no preço, não resista a vender-lhe o seu produto, ao invés de entregá-lo à sua cooperativa, deslembrando de que, debilitando-a com sua defecção, Ihe retira a capacidade de competir, e o poder de atuar, no mercado, como elemento moderador da especulação baixista.

6. Revlsta clt., ano 1967, t. 59 , págs. $102-103$.

7. Revlsta cit. t. 54 , pág. 403

8. Apud SCHMOLDERS, op. et. loc. cit.

9. Op. clt., pág. 298. 
Por outro lado, alcançando a elevada taxa do ICM precisamente, por inteiro, o valor das primeiras operações, constitui ela, por si só, tentação permanente ao "pecado" da sonegação, especialmente quando o resultado desta favorece sensivelmente ao sonegador. "Não há dúvida - afirma o Prof. RICHARD KERSCHAGL - que a improbidade tributária aumenta na medida em que sobem as taxas dos impostos, ao passo que ela diminui na proporção da redução das mesmas taxas, e isto provavelmente em escala progressiva" 10 .

A sonegação praticada pelo "atravessador" na zona rural serve de exemplo a outros e os incita a procederem da mesma forma. "É uma reação em cadeia"11.

14. As cooperativas autênticas repelem, pela própria natureza de sua estrutura e dos seus fins, o recurso à fraude. Os dirigentes de cooperativas são, geralmente, administradores de um patrimônio alheio ou, quando muito, nele posssuem pequena participação. Em nada Ihes aproveita sonegarem em benefício da cooperativa quando, ao fim do exercício, o resultado das sobras, excluída a parte levada a fundo indivisivel, irá para os cooperados. Seria insânia afrontar as duríssimas penas do crime de sonegação, para servir, não a si próprio, mas a terceiros, que nem de longe reclamam de outrem tal sacrifício. Além disso, as cooperativas estão sob permanente controle do poder público, que, para resguardo da legislação aplicável e da defesa do interesse coletivo, nelas pode intervir, a qualquer momento, por iniciativa própria. Afora esses aspectos, existe a fiscalização fazendária, exercida por técnicos altamente especializados, que não se descuidam de submeter as sociedades cooperativas a constante vigilância.

15. O produto entregue pelo cooperado à sua cooperativa, dará, necessariamente, quando posto no mercado, lugar ao recolhimento do tributo. A produção entregue à cooperativa, quando colocada, é fonte de recursos para o erário estadual. O produto desviado para as mãos do "atravessador" realiza a sua circulação clandestina, sem deixar nenhum benefício para o tesouro público. Bastaria isso, do ponto de vista meramente fiscal, e abstraindo razões sócio-econômicas complementares, para que o Poder Público criasse as necessárias condições objetivas para,

\footnotetext{
10. Finanzwissenschaft, ed. 1935, pág. 83.

11. FRANÇOIS MOMBERT, Revista cit., pág. 467.
} 
mediante incentivos tributários adequados, ocasionar o afluxo da produção do cooperado para a cooperativa, onde o interesse do fisco, na percepção do tributo, estaria devidamente resguardado.

16. Quando preconizamos a criação de um regime de incentivos fiscais para os setores da economia cooperativada, excluímos, de imediato, a idéia de uma isenção tributária, geral, indiscriminada e sem controle às sociedades cooperativas.

Entendemos que, neste particular, os benefícios que forem concedidos devem visar, como ponto fundamental, ao aprimoramento da mecânica do sistema cooperativista, favorecendo a integração ou concentração vertical das empresas cooperativas, concorrendo para a melhoria do seu padrão técnico, por meio da formação de administradores altamente capacitados, da introdução de métodos modernos e racionais de trabalho, além de outras medidas destinadas a educar, solidariamente, para a prática consciente da ajuda mútua, a massa dos associados.

17. Minimizar a importância do cooperativismo na economia nacional e entregá-lo à própria sorte nos mercados agressivamente concorrenciais em que atua - ele que historicamente surgiu e continua funcionando como instrumento de defesa de pessoas economicamente débeis contra os excessos do intermediarismo capitalista - seria, certamente, grave erro de visão por parte dos Poderes Públicos.

Países economicamente desenvolvidos não hesitam em prodigalizar favores fiscais às cooperativas, tendo em vista a eminente função sócio-econômica, de sentido marcadamente solidarista, exercido por essas organizações.

LARCHEVEQUE, então Ministro da Agricultura da França, no 4. Congresso Internacional de Cooperativismo realizado em 1963, em Viena, assim se manifestou a propósito do regime fiscal das cooperativas no seu país :

"Do ponto de vista tributário encontramo-nos em uma situação singular, talvez única em todos os países do mundo ocidental e que consiste em estarem todas as cooperativas agrícolas totalmente livres de impostos. Trate-se de cooperativas de produção, transformação ou vendas para atendimento dos agricultores ou de cooperativas de prestação de serviços, nenhuma delas paga impostos, quer ao Estado, quer a outras corporações regionais"'12.

12. Zeitschrift für das gesamte Genossenschaftswesen, ano 1964, pág. 349 . 
Advertiu o Ministro LARCHEVEQUE que existem algumas exceções, como, por exemplo, as cooperativas de laticínios que mantêm postos de venda a varejo em certas localidades. $E$ acrescenta: "São, porém, casos pouco numerosos, de sorte que se pode dizer que as cooperativas agrícolas na França, via de regra, não pagam impostos. É certo que o Estado francês tem necessidades (financeiras) idênticas às de outros Estados, mas a importância da população rural e a sua composição social determinaram que todos os governos, na França, tivessem a preocupação de poupar a população rural e favorecer o seu labor e a sua independência"13.

Passando do Velho Mundo para os paises jovens da América, vale destacar o depoimento de AIDA PEREZ DE FIGUEIROA, quando nos informa sobre o regime fiscal das cooperativas de Porto Rico :

"Em Porto Rico a cooperativa está isenta do imposto sobre o patrimônio no montante de 100.000 \$, e nenhuma cooperativa paga imposto de renda, muito embora a lei autorize as cooperativas a realizarem operações com terceiros até $50 \%$ do volume total de seus negócios"14.

18. A benevolência no tratamento fiscal dispensado, em paises desenvolvidos ou menos desenvolvidos, às organizações cooperativas, não se inspira, evidentemente, em razões disparatadas, de puro arbítrio, mas no reconhecimento da instrumentalidade não só econômica, senão também social, educativa, cultural e, principalmente, solidarista dessas organizaçöes.

19. Em mensagem de 31-1-1964, dirigida ao Congresso dos Estados Unidos, o Presidente JOHNSON destacou, com palavras de estímulo, a importância sócio-econômica da cooperação:

"Os agricultores deviam ser incentivados a afirmar, com as próprias forças, o seu lugar no mercado, servindose, para esse efeito, da organização cooperativa. Neste sentido, desde muitos anos, orientou-se a política do Congresso, e os vultosos investimentos, exigidos pelo progresso técnico, são responsáveis pela necessidade, cada vez maior, com que se defrontam as cooperativas de assumir,

13. Ibidem 
a bem dos agricultores e no interesse de uma mais alta rentabilidade agrícola, tarefas que se relacionam com a colheita, estocagem, elaboração, transporte e colocação nos mercados"'15.

20. No Brasil, estas e outras tarefas também se inserem no elenco das atividades cooperativistas, sobretudo nas zonas rurais que, evidentemente, não apresentam o elevado padrão técnico e educacional dominante nas áreas de produção agrícola da poderosa nação norte-americana. Aqui ainda incidem, em vastas regiões, os fatores negativos a que se refere o recente "Relatório Rockefeller" no relato que faz das "condições de vida nas Américas" : - "vida de nivel pobre e pouca educação para o homem rural; uso insuficiente da terra; falta de eqüidade na distribuição da terra; crédito inadequado e serviços conexos insuficientes; falta de pesquisa agrícola básica e aplicada; preços baixos e incertos para os produtos; falta de instalações e acondicionamento, estocagem e comercialização; e falta de nutrição e boa saúde, iniciativa, imaginação e administração agrícola - tudo o que, por sua vez, é causado principalmente pela pobreza e falta de educação"16.

21. É certo que em muitas faixas de nosso hinteriand, esses fatores negativos já foram ou estão sendo paulatinamente superados. Mas seria ilusório admitir que o problema global da produtividade agrícola, no seu aspecto qualitativo e quantitativo, não constitua, ainda hoje, um dos mais sérios desafios à capacidade realizadora da Nação.

22. Se existem problemas nos campos, também os há nos centros urbanos.

Nos campos, impõe-se a necessidade urgente de aumentar-lhes a produtividade, pela atuação de uma assistência sanitária, intelectual e educativa, endereçada à valorização do homem rural, e, de modo especial, mediante a introdução de novas técnicas de exploração agrícola, capazes de arrancar, nas regiões menos desenvolvidas, os camponeses, atualmente abandonados à própria sorte, das tenazes de uma economia de mera subsistência.

15. Cf. Dr. GERHARD SCHACK, "Raiffeisen in Deutschland", em 1965, pág. 65.

16. As Condiçōes de Vida nas Américas, Texto completo do Relatório Rockefeller, editora "Distribuidora Record* Rio - São Paulo, pág. 124. 
Nas cidades, ressalta o problema da defesa do poder aquisitivo dos consumidores, castigados por movimentos altistas cíclicos, em que os preços oscilam e flutuam, arbitrariamente, em uma mesma unidade de tempo, de uma para outra casa de negócio, ao capricho de uma comercialização incontrolável.

A associação cooperativa, supervisionada pelos poderes públicos, tecnicamente dirigida e cientificamente organizada, ainda se apresenta, pelo seu valor solidarizante, como o meio mais adequado para orientar, fomentar e estimular as atividades rurais, e corrigir, por outro lado, as reiteradas distorções de mercado que se verificam nos centros consumidores.

23. Tornou-se um truísmo, na linguagem de todos os dias, a insistente afirmação de que não é possivel o pleno desenvolvimento sem a criação de um mercado interior, em que a indústria, alimentada pela produção primária, encontre na cidade e nos campos o necessário poder de compra de suas manufaturas.

O empreendimento cooperativo, conquanto pela sua estrutura comunitária não seja somente empresa, embora também se revista do caráter de empresa, poderá contribuir, quando técnica e racionalmente conduzido, de maneira decisiva, para a criação desse mercado interior.

Trata-se de um problema comum aos países de economia subdesenvolvida ou em vias de maior ou menor desenvolvimento.

Examinando o assunto com a arguta visão do analista habituado à avaliação dos fatos econômicos, o Professor REZSOHAZY assim se pronuncia a respeito:

"La clave del problema de los países subdesarrolados desde el punto de vista económico es, en consecuencia, la creacion de um mercado interior, o dicho de otro, la formacion de um poder adquisitivo en expansion continua y regular.

"Esta tarea fundamental asigna al Movimiento Cooperativo su primera vocación en el campo económico. Consiste en esforzarse com ahinco en crear este mercado interior, en aumentar el nivel de vida $\mathrm{y}$, consecuencia, el poder adquisitivo.

"De este modo, el Movimiento Cooperativo puede no solamente contribuir a influenciar de uma manera determinante la formación de mercados, sino que tiene tam- 
bién la ocasión de llegar a ser la corriente que determine el sistema económico que adoptarán los países jóvenes.

Queda por saber, cómo se crearán, tomarán formn, se construirán, ses extenderán los diferentes compartimentos del mercado interior.

"Sin querer limitar los diferentes medios posibles, enumeraré seis vias que son essenciales : la organización del ahorro, eliminación de las prácticas usureras, reforma agraria, racionalización de la distribución, creación de uma infra-estrutura económica y educación de la problación. Cada una de estas tareas influye decisivamente sobre el nivel de vida y contribuye a formar mercados. En cada una de ellas el papel de las Cooperativas puede ser determinante"17.

24. Mas não é só nos países subdesenvolvidos ou em vias de desenvolvimento que as cooperativas realizam a importante função de dinamizar a economia nacional. Essa missão também a executam em países que acusam os mais altos índices de desenvolvimento. Assim, acentua o Dr. GERHARD SCHACK, referindo-se às cooperativas da Alemanha Ocidental :

"As cooperativas participaram decisivamente, nos últimos decênios, no enorme aumento da produção agrícola. Desde os tempos de RAIFFEISEN auxiliaram elas aos seus associados na adoção de métodos econômicos cada vez mais eficientes, desse modo servindo ao progresso técnico da agricultura. Elas contribuiram no sentido de que os créditos e os insumos, proporcionados aos cooperadores, fossem utilizados pela forma mais produtiva e racional, com perfeita observância das recomendações oficiais e privadas"18.

25. A razão que torna aconselhável incentivar a integração cooperativa na área rural, no interesse do desenvolvimento econômico e da estabilidade das relações sociais, é posta em relevo pelo Dr. SCHACK com palavras simples, mas que convencem pela sua lucidez:

17. Professor R. REZSOHAZY, "Tareas actuales del Movimento Cooperativo em la Economia de Mercado", in "Estudios Cooperativos n. 6" - Madrid 1964, pág. 7.

18. Dr. GERHARD SCHACK, op. cit., pág. 45.

R. Serv. públ., Brasília, 109 (1) jan./mar. 1974 
"O comerciante leva vantagem sobre o pequeno ou médio agricultor, isoladamente considerado, não só do ponto de vista financeiro, senão também pelo melhor conhecimento dos mercados, quer no que tange à aquisição de utilidades, quer, em grau muito maior, no que respeita à comercialização das safras. As centenas de milhares de pequenas ou médias unidades agrícolas, só podem alcançar por intermédio da união cooperativa, um resultado econômico satisfatório e uma adequada participação no produto social. A organização cooperativa presta-se, como nenhuma outra, para servir à agricultura como fator de ordem nas relações de mercado. Trata-se, no caso, de atuar como fator de compensação e de regulação dos preços. Para aliviar o mercado, controla-se a oferta maciça nos períodos de safra; a produção excedente é industrializada ou estocada. O objetivo é assegurar, de antemão, um abastecimento, tanto quanto possível, regular dos mercados"19.

26. Tendo em vista o incontestável valor social do associativismo cooperativista, especialmente no setor da produção primária, sobretudo em países que lutam pelo aumento dos seus indices de produtividade, cabe ao Poder Público, no exercício de uma fiscalidade racionalmente orientada, propiciar, através de incentivos tributários equidosos e razoáveis, adequadas condições de competição e desenvolvimento às organizações cooperativas.

Em princípio, como assinala JOSÉ LUIS DEL ARCO, as razões que se esgrimem para reclamar um tratamento especial para as cooperativas, podem ser assim sintetizadas:

"Las Cooperativas suelen estar formadas por gentes económicamente débiles, $\mathrm{y}$, por tanto, la ventaja pretendida no es más que aplicación del critério establecido por las leyes fiscales en favor de las personas de escasos ingresos o de actividades de mínima cuantia en su estimación y rendimientos.

"Las Cooperativas - o determinadas clases de éstas - cumplen una función social transcendente, merecedora de protección, lo mismo cuando asocian elementos produtores que cuando procuran la obtención de un crédito barato o, en fin, si agrupan a los consumidores para acrecer su capacidade de compra, y no sólo por sus actividades económicas, sino por la contribución que prestan

19. Cf. Dr. GERHARD SCHACK, op. cit., pág. 45. 
a la elevación social y cultural de las clases modestas de la sociedad.

"Finalmente, el tratamiento fiscal de las Cooperativas, en general, no puede ser el mismo que el de las sociedades mercantiles o especulativas, por su distinta naturaleza, organización y modo de operar"20.

27. Esta última observação tem inteira razão de ser. Realmente, é princípio universalmente aceito e proclamado nas próprias legislações, que as cooperativas se revestem de características de estrutura e de atuação, interna e externa, que as distingue, marcadamente, das sociedades de capital.

Como acentua HELMUT FAUST, em lúcido ensinamento: "Em oposição a empreendimentos mercantis, que objetivam alcançar os mais altos lucros possíveis, a empresa cooperativa funciona na base do princípio da cobertura dos custos operacionais" 21.

\section{E, mais adiante :}

"A idéia, fundamental da associação cooperativa é - servir, não lucrar! Se o empreendimento cooperativo, no fim do exercício, apurar excedentes, voltam eles, em regra na proporção da participação nos serviços comuns, sob a forma de retorno, aos associados. Esta regra, de dividir os excedentes com base na participação pessoal, e não financeira, dos associados nas operações da empresa, nada mais é senão a expressão da idéia de servir. Esse princípio, que singulariza a empresa cooperativa, permite distinguí-la de quaisquer outras formas empresariais. Quase sem exceção, todos os líderes do movimento cooperativista, que se ocuparam mais detidamente com o estudo da natureza dessas organizações, sempre acentuaram, ontem como hoje, que o objetivo primordial da cooperativa é, por sem dúvida, de natureza econômica, mas que esse fim é alcançado por outro caminho que não o da empresa capitalista ou coletivista, caracterizadas ambas como sistemas econômicos que conduzem à massificação"22.

20. JOSE LUIS DEL ARCO, "Consideraciones sobre el régimen fiscal de las Cooperativas", In "Estudios Cooperativos", n. 6 - Madridd 1964, pág. 53.

21. Cf. Geschichte der Genossenschaftsbewegung, ed. 1958, pág. 63.

22. Ibldem.

R. Serv, públ., Brasília, 109 (1) jan./mar. 1974 
E diz mais o escritor ilustre :

"A cooperativa moderna é, como assinala GERHARD WEISSER, primordialmente "sociedade no sentido sociológico". Mas dentro dela costuma formar-se um espírito comunitário, não se podendo negar que corresponde à intenção da maior parte dos amigos do cooperativismo que, entre eles, se constitua uma comunidade. É certo que os comportamentos dos cooperados e suas relações para com a cooperativa são muito diversificados, razão pela qual a estrutura sociológica da cooperativa se torna de difícil conceituação, não se encontrando uma norma validamente aplicável a todos os tipos de cooperativas.

"Muito embora, porém, as relações humanas entre os cooperados não sejam de tamanha densidade que possamos atribuir às cooperativas a caracterização sociológica de "comunidade", conforme o conceito introduzido na sociologia por FERDINANDO TONNIES existe contudo uma força vinculante, que não só anima os membros dos grupos cooperativos, isoladamente considerados, mas todos os individuos que participam do movimento cooperativista. É o espírito grupal, o espírito comunitário, induzido do reconhecimento vivo de que as cooperativas são mais do que uma simples união destinada à fruição de interesses econômicos, mas que nelas também atuam forças construtivas extra-econômicas, de natureza ética e espiritual'"23.

28. A estrutura peculiar da associação cooperativa, condicionante de comportamentos solidaristas e formadora de uma consciência de entre-ajuda, inexistente nas organizações tipicamente lucrativistas, recomenda, como de boa política, que as suas virtualidades sejam aproveitadas pelo Poder Público para a criação de novas fontes de riqueza, saúde, educação e fraternidade social, especialmente nas classes mais desprotegidas da população urbana e rural, sempre sensivel e reconhecida às iniciativas governamentais que objetivem a elevação do seu padrão de vida.

29. Um dos instrumentos utilizáveis para a consecução desses fins, ainda continua sendo a isenção tributária, total ou parcial, como se colhe dos exemplos da França e de outros países do velho e novo continente.

"Estimamos - acentua DEL ARCO — de absoluta justicia el mantenimiento de exenciones fiscales para de-

23. Helmut faust, op. cit., pág. 65. 
terminadas clases de cooperativas, en atención a la modéstia económica de las mismas, o por el interés público de estimular esta forma de associación en amplios campos da actividad económica, seguros de que los beneficios que se obtendrán - creación de nuevas fontes de riqueza, regulación de mercados, lucha contra la usura y monopólios, humanización de la economia frente a la deshumanización del capitalismo, elevación de clases sociales modestas etc. compensarán sobradamente el aparente sacrificio fiscal'"24.

30. As isenções tributárias, quando usadas, racionalmente, no interesse da expansão da economia do país; na correção de desajustamentos econômicos e financeiros ocasionados pelas evasões fiscais ilicitas, que enriquecem a alguns, empobrecem a muitos e prejudicam a coletividade como um todo; na melhoria da saúde física e mental da população, através da prestação de serviços médicos, farmacêuticos, pedagógicos e outros tantos capazes de valorizar o homem e prepará-lo, convenientemente, para o exercício de tarefas úteis para si, para sua família e para a pátria; - não é possível negar que, neste caso, as isenções fiscais, bem orientadas e conduzidas, não violam o princípio constitucional da isonomia, que nunca teve o significado de uma igualdade absoluta perante as normas in fieri, i.e, objeto de elaboração e edição pelo Poder Legislativo.

"PONTES DE MIRANDA observa, com toda a razão, que a "lei igual para entes desiguais (física e economicamente) é uma ignomínia, porque coloca fortes e fracos, ricos e pobres, sábios e ignorantes, no mesmo plano legal, a lei igual pressupõe, como ensinam os tratadistas yankees, iguais condições e circunstâncias, sob pena de se instituir "a mais cruel desigualdade, na expressão de SAMPAIO DÓRIA"25.

"Por isso mesmo é que JOÃO MANGABEIRA, um dos mais autorizados corifeus da socialização do Direito no País, observou que "consiste a igualdade júrídica, sobretudo, em considerar desigualmente situações desiguais, de modo a abrandar, tanto quanto possível, pelo direito, as diferenças sociais e por ele promover a harmonia social, pelo equilíbrio dos interesses e da sorte das classes" 26 .

24. JOSE LUIS DEL ARCO, op. cit. pág. 62.

25. Cf. PAULINO JACQUES, "Da Igualdade perante a lel", pág. 162.

26. Ibidem.

R. Serv. públ., Brasília, 109 (1) jan./mar. 1974 
As cooperativas, tanto pela estrutura, como pelos fins, são essencialmente diferentes das sociedades de capital. As diferenças de caráter comunitário, ético e cultural que, no caso, ressaltam em favor da imagem institucional das organizações cooperativas, autorizariam, por si só, com pleno respeito ao princípio da isonomia, dispensar-Ihes um tratamento fiscal mais benigno, destinado a estimular sua expansão e desenvolvimento.

31. Não se trata, porém, na hipótese, de sugerir uma concessão pura e simples de favores tributários.

A situação especial das cooperativas, particularmente nas zonas rurais, onde ainda impera o quadro negativo apontado no "Relatório Rockefeller", justifica que se adotem, na esfera tributária, medidas adequadas para transformar essas organizações em instrumentos de ação política e social dos poderes públicos, com o fim de promover o desenvolvimento nacional.

No elenco dos impostos, aquele que, sem embargo da isenção instituída pelo Decreto-lei n. ${ }^{\circ} 406 / 68$ e ratificada pela Lei Complementar n. ${ }^{\circ} 4 / 69$, maiores desajustamentos tem causado na área cooperativa, é o ICM.

Nos Estados que consagraram o regime do "diferimento da incidência" do ICM no âmbito da produção primária, agrícola ou pastoril, como, por exemplo, no Rio Grande do Sul, a isenção da Lei Complementar n.० 4/69 não tem o menor valor ou significação. As cooperativas de produtores rurais, apesar da intenÇão protetora do legislador federal, concretizada na outorga da isenção, entretanto, em razão do "diferimento da incidência" estabelecido pela legislação estadual, continuam a operar à sombra do mesmo tratamento fiscal, em absolutas condições de igualdade com as empresas não-cooperativas.

32. Se a tese da "isenção" do ICM para os produtores cooperativados já obteve aceitação no Legislativo Federal, cumpre reexaminá-la, atentamente, para o encontro de uma fórmula de estímulo tributário que não represente uma injustiça para a área empresarial não-cooperativada, mas que também não constitua uma solução ilusória, sem qualquer reflexo sobre as possibilidades de aperfeiçoamento e dinamização do sistema cooperativista.

33. A pulverização do produto da isenção do antigo imposto de vendas e consignações nas mãos de cada unidade cooperativa, isoladamente considerada, indica, pela negatividade dos 
seus resultados práticos no passado, que não é este o melhor caminho a seguir na exoneração, total ou parcial, das cooperativas do ICM.

O alívio fiscal só pode ser concedido sob a forma de "incentivo" ao aprimoramento das atividades cooperativas e, precisamente, mediante aplicação daqueles processos que permitem atingir, com segurança, o fim proposto.

A regra que, neste caso, deve nortear o Poder Legislativo está expressa, de forma magistral, neste pronunciamento, sábio e lapidar, do eminente Chefe da Nação:

"Orientaremos os incentivos fiscais e crediticios para finalidades muito mais de profundidade que de superfície, de tal forma que os investimentos não se dispersem, não se pulverizem, não se malbaratem em iniciativas oportunistas, enganadoras, artificiais ou inconsistentes, antes se concentrem em cometimentos multiplicadores, produtivos, permanentes, capazes de realizarem a verdadeira humanização de tanta paisagem ainda sub-humana"27.

34. O incentivo fiscal, proporcionado mediante adequada isenção do ICM, só pode ser instituído por Lei Complementar, pois importa em intervenção da União na competência tributária dos Estados $^{28}$.

A rentabilidade do incentivo deve ser condição essencial para a sua concessão, ou, em outros termos, o montante do incentivo fiscal deve produzir frutos positivos tanto no aperfeiçoamento empresarial da organização cooperativa, como na prestação cada vez mais eficiente dos seus serviços ao verdadeiro titular do empreendimento, que é o cooperado individual.

35. A melhoria do serviço prestado ao associado singular, porém, nem sempre está ao alcance de uma cooperativa de pequeno porte ou de âmbito local.

"Para a execução de tarefas maiores - como acertadamente observa o Dr. GERHARD SCHACK - torna-se mister unificar a comercialização da produção agrária, em nível estadual ou nacional, por intermédio de estabelecimentos centralizadores. E

27. Presidente MÉDICI, "O Jogo da Verdade", pág. 65.

28. Constituiçåo Federal, art. $19, \S 2.0$

R. Serv. públ., Brasília, 109 (1) Jan./mar: 1974 
por meio das Cooperativas Centrais que, via de regra, se alcanÇa a rota para o mercado, a conexão com a economia nacional. Somente as Centrais podem oferecer suporte e respaldo às cooperativas locais na colocação concorrencial de sua produção no plano internacional. A mesma função que às cooperativas singulares cabe exercer em face dos seus associados, isto é, serviremthe de empreendimento auxiliar e prolongamento de suas economias individuais, incumbe à Central em relação às suas filiadas; também ela não constitui um fim em si, mas um membro prestativo na organização global" 29 .

36. Trata-se do fenômeno econômico da integração ou concentração vertical das empresas, a cuja influência as cooperativas - empresas que são - se não podem subtrair no interesse da melhoria técnica do seu funcionamento ou, talvez, até mesmo, de sua própria sobrevivência.

BENSON, quando Ministro da Agricultura dos Estados Unidos, teve ensejo de abordar o problema no setor das atividades agrárias :

"A exploração agrícola vinculada a contratos ou outras formas de integração vertical faz parte dos mais poderosos fatores da nossa moderna agricultura. Mediante a renúncia parcial à execução autônoma de certas tarefas e da respectiva transferência a terceiros, a integração do agricultor poderá influir decisivamente sobre a sua posição na atual economia agrária. O agricultor, entretanto, deve examinar, com cuidado, o que lhe é oferecido em troca da perda de sua liberdade de ação... Uma das vias pelas quais tanto os grandes como os pequenos agricultores poderão entrar no gozo de medidas integradoras, é aquela que conduz à sua participação nos serviços das cooperativas rurais" 30 .

37. No sistema cooperativista, a integração se faz por meio da descentralização de funções, vale dizer, a "construção federativa" ou a integração vertical se faz de baixo para cima ${ }^{31}$. E o contrário do que ocorre no setor capitalista, onde a concentração vertical se faz de cima para baixo, cabendo ao organismo

29. Cf. Ralffeisen in Deutschland, pág. 46

30. Cf. Agricultural Information Bulletin, n. 198

31. JOSEF M. ВACK, "Wo stehen die Genossenshaften Heute", pág. 57. 
de cúpula (Konzern) comandar os empreendimentos nele congregados.

Como assinala PFüLLER : - "As cooperativas são os suportes das centrais regionais e estas, por sua vez, servem de base aos institutos de grau superior. A missão fundamental de toda essa organização é a proteção dos interesses dos cooperados" 32 .

38. A observação do sistema cooperativista, no seu conjunto, e, de modo especial, nos seus diversos ramos de atividade, permite constatar, na opinião de WEIPPERT, que foram as Centrais que influiram de tal sorte sobre as cooperativas singulares, formadas para a proteção e defesa dos sócios, que chegaram a transformá-las, por meio das relações intra-cooperativas, em formas associativas dinâmicas, com ativa participação no mecanismo dos mercados ${ }^{33}$.

"Também, de futuro, acrescenta PFüLLER, tornarse-á necessário promover o desenvolvimento das Centrais para poderem assegurar a capacidade funcional das cooperativas singulares e, se possivel, fortalecê-la" 34 .

39. Tendo em vista esses aspectos que também são comuns ao cooperativismo brasileiro, onde as Centrais e Federações atuam, diretamente, a serviço das cooperativas singulares e, indiretamente, no interesse dos respectivos cooperados individuais, parece razoável que os favores fiscais que, mediante isenção parcial do ICM, forem concedidos ao setor empresarial cooperativo, devem concentrar-se, perfeitamente, nas organizações de grau superior - Centrais e Federações - ao invés de pulverizar-se em poder das cooperativas de primeiro grau.

A utilização racional de recursos de maior vulto, em programas de aplicação tecnicamente orientados, permitirá a realização unitária e global de empreendimentos (econômicos, culturais, científicos etc.) de interesse coletivo, que a cooperativa singular, com suas próprias forças, não estaria em condições de executar.

32. REINER PFOLLER, Der Genossenschaftsverbund, ed. 1964, pág. 1.

33. Cf. REINER PFOLLER, op. cit., pág. 105.

34. Ibldem.

R. Serv. públ., Brasília, 109 (1) Jan./mar. 1974 
40. Finalmente, se os recursos obtidos pard 8 aperfeiçoamento do sistema são originários da liberalização de frações de tributos, de que o erário abre mão no interesse d $\$$ / @esenvolvimento nacional, justifica-se que o Poder Público que propictot tais recursos, se reserve, por igual, o controle sobre a sua aplicação.

fins O rigoroso emprego dos incentivos fiscais na exécução do's ven objetivados pela lei, seria assegurado por meio de um conveniente mecanismo de sanções, destinado a prevenir, nos limites do possível, eventuais distorções e desvios.

41. A fórmula fiscal (concentração da redução do ICM nas Centrais e Federações) apresentada, neste estudo, para o aprimoramento do sistema cooperativo, nos seus aspectos econômicos, empresariais, sociais etc., corresponde, em termos gerais, à aplicação prática dos princípios da extrafiscalidade, largamente empregada nos Estados modernos e também aqui já incorporada, definitivamente, como instrumento de atuação desenvolvimentista, à filosofia política do Governo Nacional.

"Os estímulos fiscais, no Brasil, encontram larga aplicação, como são exemplos os dados pela União por meio do imposto sobre a renda para o desenvolvimento da região da SUDENE e SUDAN ou para o desenvolvimento da pesca, do turismo, do florestamento e reflorestamento etc.".

"Através de medidas fiscais que excluem total ou parcialmente o crédito tributário o Governo Central procura provocar a expansão econômica de uma determinada região ou de determinado setor de atividade" 35 .

Es. Os fins extrafiscais tanto podem ser alcançados pelo Estado mediante o estabelecimento de tributos específicos utiliZáveis em tal ou qual sentido de interesse público, como por meio de isenções tributárias, totais ou parciais, que sirvam de estimulo ou incentivo à criação ou expansão de atividades, instituições, formas e estruturas sociais consideradas úteis ao equilíbrio e desenvolvimento da vida coletiva.

ceir O ICM, embora criado para atender às necessidades finandes dos Estados-membros, pode ser manipulado com finalidaextrafiscais ${ }^{36}$, através de um sistema racional de isenções ou

\footnotetext{
35. RUY BARBOSA NOGUEIRA, Direito Tributário, 1.• ed., 1969, pág. 65.

36. PAULO ROBERTO CABRAL NOGUEIRA, "A Reforma Tributária e Sua Mais Importante Inovação: I.C.M." in Direito Tributário, de RUY BARBOSA NOGUEIRA, pág. 339; MANOEL LOURENÇO DOS SANTOS, "Direito Tributário", 3.^ ed. pág. 241.
} 
reduções instituído mediante convênios firmados por unidades federativas integrantes de uma dada região geo-econômica, na forma hoje prevista no artigo $23, \S 6 .^{\circ}$ da Emenda Constitucional $n .^{\circ}$ 1 , ou, no plano nacional, por meio de Lei Complementar editada pela União no exercício da competência que Ihe é atribuída pelo artigo $19, \S 2 .^{\circ}$ da Constituição $0^{37}$.

43. Hoje, o movimento cooperativo extravasou das fronteiras dos Estados-membros, para, sob a direção da Organização Brasileira de Cooperativas, processar-se em âmbito nacional. No plano interestadual também se desenvolvem as atividades econômicas de numerosas cooperativas. Nestas condições, uma politica de incentivos fiscais ao cooperativismo, mediante utilização do ICM, que é o imposto de maior impacto sobre as possibilidades competitivas das organizações cooperativistas, só poderia lograr pleno êxito quando dimensionada em nivel nacional.

Os incentivos de caráter local importariam em pulverização de recursos. A concentração dos incentivos em Centrais ou Federações parece-nos condição essencial à rentabilidade de sua aplicação. As Centrais ou Federações, porém, têm por mercado - Brasil, quando não o exterior. Só o Governo Central, por meio de Lei Complementar, pode utilizar com resultados positivos a isenção ou redução do ICM no desenvolvimento integrado do cooperativismo e, conseqüentemente, na desejada dinamização das virtualidades sócio-econômicas inerentes ao sistema.

44. A isenção parcial do ICM, estimada, por exemplo, em $20 \%$ do tributo, seria canalizada, sob a forma de incentivo ao cooperativismo, para as Centrais e Federações de Cooperativas, na proporção dos recolhimentos fiscais realizados pelas entidades associadas.

45. O valor dos incentivos, contabilizados em conta especial nas entidades de grau superior, seria aplicado, por intermédio destas, em benefício da melhoria do padrão técnico próprio e das cooperativas filiadas, bem como na objetivação de outros fins de interesse comum, de conformidade com uma programação previamente estabelecida, aprovada, anualmente, em reunião de Assembléia Geral da Central ou Federação.

46. Observados tais critérios, a aplicação dos incentivos não implicaria pulverização de recursos. Pelo contrário, as Centrais e Federações, fortalecidas pelo afluxo financeiro do valor

37. RUY BARBOSA NOGUEIRA, op. cit. pág. 63 e ss.

R. Serv. públ., Brasília, 109 (1) jan./mar. 1974 
dos incentivos, não só ficariam elas próprias, senão também suas associadas, em situação de competir, em condição de igualdade, com o setor das empresas não-cooperativas, geralmente bem mais capitalizadas e, muitas delas, poderosamente aparelhadas, técni$\mathrm{ca}$, funcional e crediticiamente, para o exercício da concorrência.

47. Robustecido o sistema empresarial cooperativo, os resultados de interesse público imediatamente se fariam sentir:

a) nas cooperativas rurais, aumentaria o volume de produtos primários entregues pelos associados, reduzindo o custo operacional da organização e permitindo-lhe desempenhar, em benefício dos produtores, as suas funções de reguladora dos preços de tais produtos nas relações de mercado;

b) em conseqüência, com o incremento do volume das entregas efetuadas pelos cooperados, reduzir-se-ia a comercialização da produção primária no mercado clandestino, onde opera o "atravessador", em manifesto prejuizo do fisco. Diminuída a sonegação, receberia o fisco, através dos recolhimentos tributários das cooperativas, as parcelas de ICM que, em virtude da comercialização clandestina, se perdem para o erário;

c) suprida a natural debilidade econômico-financeira das cooperativas rurais - constituídas, em sua grande maioria, de pequenos produtores, muitos deles minifundiários - poderiam elas auxiliar e estimular, com maior vigor, seus cooperadores no exercício de suas atividades agropecuárias, possibilitando-lhes um aumento de produtividade que, por sua vez, se converteria, no curso do tempo, em maiores entregas de produção à cooperativa. Na medida em que aumentasse a produção comercializada pelas cooperativas, com preços, não aviltados, mas razoáveis, estáveis e justos, a tributação pelo ICM também ficaria enriquecida, com manifesta vantagem para o tesouro público;

d) dentro desta problemática e dos resultados econômicos e fiscais conferidos por meio dos incentivos, é força admitir que 0 aparente sacrifício da isenção parcial, acima indicada, de $20 \%$ do ICM em favor das empresas cooperativadas, ficará, em pouco tempo, suficientemente compensado pelo recolhimento certo e crescente do tributo, efetuado pelas cooperativas; 
e) quanto ao percentual - digamos, de $30 \%$, dos incentivos - aplicado pelas Centrais e Federações na preparação de técnicos em administração de empresas, na criação e manutenção de auditorias cooperativas e, de modo geral, na melhoria do nível educacional, tecnológico e cultural dos produtores associados, estaria a Administração Pública, por esse meio, realizando, talvez com menor dispêndio, aquelas funções essenciais, de interesse coletivo, que, em razão de seus próprios fins, incumbem aos entes políticos - União e Estados-membros. 